FERMILAB-TM-1718

\title{
Transrex 500 kW Power Supply Transductor Upgrades
}

\author{
W. Jaskierny \\ Fermi National Accelerator Laboratory \\ P.O. Box 500 \\ Batavia, Illinois 60510
}

March 4,1991 
March 4, 1991

W. Jaskierny

TM \#1718

Cat \#2080.000

\section{TRANSREX $500 \mathrm{~kW}$ \\ POWER SUPPLY TRANSDUCTOR \\ UPGRADES}




\section{SUMMARY}

This paper describes various upgrades and tests done at the Research Division $500 \mathrm{~kW}$ Transrex power supply dc current transductors and chassis. The results of all modifications were measured on the same test setup with the same transductor head and chassis. The setup used for the measurements is shown in Fig. 1. Field testing of over one-hundred power supplies indicated that the results given in this paper are similar to the signals observed in the field within a factor of + or - two. The dc transductors yield $10 \mathrm{Vdc}$ burden resistor voltage at $5000 \mathrm{~A}$ load current.

\section{DESCRIPTION OF TESTS AND CIRCUIT CHANGES}

\section{Reference}

The transductor head and chassis as built by Transrex was studied at 3 operating points which were: zero Amp, $500 \mathrm{Amp}$, and $2000 \mathrm{Amp}$ dc current. The original Transrex schematic is shown in Fig. 3 . The voltage ripple across the burden resistor at these 3 points is shown in Figs. 2A, 2B, and 2C. The spectrum analysis of this voltage at $2000 \mathrm{Amp}$, which results in $4 \mathrm{Vdc}$ burden resistor voltage shows the burden voltage to contain the following components:

$\begin{array}{rrrr}60.0 \mathrm{~Hz} & \text { at } & 6370.0 & \mu V_{\text {rms }} \\ 15.0 \mathrm{~Hz} & \text { at } & 22.4 & \mu V_{\text {rms }} \\ 9.2 \mathrm{~Hz} & \text { at } & 8.2 & \mu V_{\text {rms }} \\ 4.6 \mathrm{~Hz} & \text { at } & 5.0 & \mu V_{\text {rms }}\end{array}$

There was additional harmonic noise above $60 \mathrm{~Hz}$, in the burden voltage, however these harmonics have little effect on the actual beamline operation of these power supplies. This data is therefore not presented in this report.

\section{Change \#1}

The first change in the chassis was a change of R41 and R42 (Fig. 3) in the sense winding bridge from $1 \mathrm{k} \Omega, 1 \%, 10 \mathrm{~W}$ to $75 \Omega 1 \% 10 \mathrm{~W}$. The result of this was a factor of 2 reduction in the peak to peak ripple of the voltage signal seen on the 
burden resistor. This is shown in Figs. 4A, 4B and 4C. At $2000 \mathrm{Amp}$ and $4.0 \mathrm{Vdc}$ burden voltage the ripple was:

$\begin{aligned} 16.0 \mathrm{~Hz} & \text { at } & 2290.0 & \mu \mathrm{V}_{\mathrm{rms}} \\ 15.0 \mathrm{~Hz} & \text { at } & 100.0 & \mu \mathrm{V}_{\mathrm{rms}} \\ 9.2 \mathrm{~Hz} & \text { at } & 62.6 & \mu \mathrm{V}_{\mathrm{rms}} \\ 4.6 \mathrm{~Hz} & \text { at } & 33.7 & \mu \mathrm{V}_{\mathrm{rms}}\end{aligned}$

\section{Change \#1 and \#2}

The next upgrade was the replacement of the original amplifier board by a new amplifier board, shown in Fig. 5. The original boards were in poor electrical and mechanical condition due to corrosion and aging. The original board needed to be replaced. At this time it was noticed that there were also certain low frequency noise components in the burden resistor signal when the booster was running, in particular a $15 \mathrm{~Hz}$ component. These low frequency components were not present in the power supply current when the same power supply was run in a voltage regulated mode. These low frequency components resulted in a modulation of the power supply output current with $15 \mathrm{~Hz}, 9.2 \mathrm{~Hz}$ and $4.6 \mathrm{~Hz}$ in the current regulated mode. It was decided to sacrifice a percentage of the $60 \mathrm{~Hz}$ noise reduction gained in change \#1 in order to reduce the low frequency noise of $15 \mathrm{~Hz}$ and lower by adjusting the break frequency of the A.C. feedback of the amplifier card. These low frequencies would be more evident in the magnetic field of beamline magnets driven by these power supplies. A gain of -10 to $-12 \mathrm{~dB}$ was realized at 4.6 to $15 \mathrm{~Hz}$. The $60 \mathrm{~Hz}$ component was still $-3 \mathrm{~dB}$ less than it was in the original chassis. Figures $6 \mathrm{~A}, 6 \mathrm{~B}$ and $6 \mathrm{C}$ show the resulting ripple on the burden voltage. At $2000 \mathrm{Amp}$, and 4 Vdc burden voltage the ripple was:

$\begin{array}{rrrr}60.0 \mathrm{~Hz} & \text { at } & 4800.0 & \mu V_{\text {rms }} \\ 15.0 \mathrm{~Hz} & \text { at } & 30.4 & \mu V_{\text {rms }} \\ 9.2 \mathrm{~Hz} & \text { at } & 11.5 & \mu V_{\text {rms }} \\ 4.6 \mathrm{~Hz} & \text { at } & 7.8 & \mu V_{\text {rms }}\end{array}$

\section{Change \#1, \#2 and \#3}

With the use of the new and faster A to D's in Research Division controls systems, there was renewed interest in getting cleaner signals from the transductor 
chassis. It was found that by using single phase excitation on the head as shown in Fig. 5., rather than 3 phase excitation as built by Transrex, the peak to peak ripple was reduced by a factor of 2 to 2.5 on any given head and chassis. A side benefit of this change was that the power dissipation in the heads sense windings was reduced by 1/3. Also, because of reduced loading on the chassis' power transformer, the feed back power supply is stiffer, enabling the different interconnected head and chassis to operate up to $6 \mathrm{~K}$ amps ramped. The chassis still retains its 3 phase power supplies for various D.C. voltages. The resulting ripple wave shapes are shown on Fig. 7A, 7B and $7 \mathrm{C}$. Single phase excitation reduces the $60 \mathrm{~Hz}$ component in the ripple by $12 \mathrm{~dB}$ and increases the 4.6 to $15 \mathrm{~Hz}$ components by 1 to $3 \mathrm{~dB}$. With these changes at 2000 Amp and $4 \mathrm{Vdc}$ burden voltage the ripple was:

$\begin{aligned} 60.0 \mathrm{~Hz} & \text { at } & 1140.0 & \mu \mathrm{V}_{\text {rms }} \\ 15.0 \mathrm{~Hz} & \text { at } & 43.6 & \mu \mathrm{V}_{\text {rms }} \\ 9.2 \mathrm{~Hz} & \text { at } & 18.9 & \mu \mathrm{V}_{\text {rms }} \\ 4.6 \mathrm{~Hz} & \text { at } & 8.7 & \mu \mathrm{V}_{\text {rms }}\end{aligned}$

At this point a frequency response test of the transductor head and electronics was run comparing the as built by Transrex head and chassis to a head and chassis with changes \#1, \#2 and \#3. The test set up involved running current through the head from a Kepco bipolar op-amp power supply at the equivalent of $1000 \mathrm{Amps}$ D.C. with a modulation of 50 Amps random noise on top of the D.C. component. For all practical purposes the frequency response was identical with the exception that the chassis with changes \#1, \#2 and \#3 was $1 \mathrm{DB}$ flatter between $5 \mathrm{~Hz}$ to $500 \mathrm{~Hz}$.

\section{Change \#1, \#2, \#3 and \#4}

With further testing it was found that the source of ripple below $60 \mathrm{~Hz}$ was due to ripple in the chassis feed back power supply voltage. For a test the $1300 \mu \mathrm{F}$ filter capacitor was increased to $10,000 \mu \mathrm{F}$. With this configuration at $2000 \mathrm{Amp}$ and $4.0 \mathrm{Vdc}$ burden voltage we find:

$\begin{array}{rrrr}60.0 \mathrm{~Hz} & \text { at } & 1300.0 & \mu \mathrm{V}_{\text {rms }} \\ 15.0 \mathrm{~Hz} & \text { at } & 7.1 & \mu \mathrm{V}_{\text {rms }} \\ 9.2 \mathrm{~Hz} & \text { at } & 3.4 & \mu \mathrm{V}_{\text {rms }} \\ 4.6 \mathrm{~Hz} & \text { at } & 6.5 & \mu \mathrm{V}_{\text {rms }}\end{array}$


This test indicated that with this current transductor the operation can be improved by using a well filtered and regulated feed back power supply. At this time there is no plan to use $10,000 \mu \mathrm{F}$ capacitors in the Research Division transductor chassis because of physical size limitations; or to regulate the feed back power supply because of the cost and man hours involved.

The 240kW Transrex and 150, 250, $500 \mathrm{~kW}$ PEI power supplies do not appear to have this problem, probably because of different head design and/or the fact that the transductor chassis is fed from a constant voltage transformer reducing the 15 $\mathrm{Hz}$ and lower burden ripple.

\section{Change \#1, \#2, \#3, \#4 and \#5}

Another area of the transductor chassis that was investigated was the silicon diodes used in the sense winding bridge rectifier. It was thought that by using an active rectifier that the forward voltage drop variation of the diodes would be eliminated. The circuit used is shown in Fig. 8. Upon testing it was found that there was a $40 \%$ reduction in the peak to peak ripple on the burden resistor at $500 \mathrm{Amp}$ and $2000 \mathrm{Amp}$ as shown in Figs. 9A, 9B, and 9C. A spectrum analysis of the ripple showed a $12 \mathrm{~dB}$ reduction in the $60 \mathrm{~Hz}$ component at $2000 \mathrm{Amp}$ and $4.0 \mathrm{Vdc}$ burden voltage. The ripple at that point was:

$\begin{array}{rrrr}60.0 \mathrm{~Hz} & \text { at } & 277.3 & \mu V_{\mathrm{rms}} \\ 15.0 \mathrm{~Hz} & \text { at } & 1040 & \mu \mathrm{V}_{\mathrm{rms}} \\ 9.2 \mathrm{~Hz} & \text { at } & 47.1 & \mu \mathrm{Vrms} \\ 4.6 \mathrm{~Hz} & \text { at } & 30.0 & \mu \mathrm{Vrms}\end{array}$

At the same operating point with a $10,000 \mu \mathrm{F}$ filter capacitor on the feed back power supply the burden ripple was:

$\begin{aligned} 60.0 \mathrm{~Hz} & \text { at } & 3640 \mu \mathrm{V}_{\mathrm{rms}} \\ 15.0 \mathrm{~Hz} & \text { at } & 10.5 \mu \mathrm{V}_{\mathrm{rms}} \\ 9.2 \mathrm{~Hz} & \text { at } & 6.7 \mu \mathrm{V}_{\mathrm{rms}} \\ 4.6 \mathrm{~Hz} & \text { at } & 14.0 \mu \mathrm{V}_{\mathrm{rms}}\end{aligned}$


Again, the cost of rebuilding the $500 \mathrm{~kW}$ Transrex transductor chassis using an active rectifier in the sense winding bridge is prohibitive. It is suspected that some of the residual ripple across the burden resistor (especially at zero Amp) is common mode noise. This is due to the fact that the sense windings are at a different potential than the burden resistor and that the heads were built without electrostatic shielding between the windings. Several shorted transductor heads have been disected and no evidence of any shielding was found.

Future current transductor heads and chassis could incorporate a regulated feed back P.S., an active rectifier on the sense winding bridge and electrostatic shielding between windings for improved performance.

\section{INSTALLED FIELD CHANGES}

Only changes 1, 2 and 3 have been installed in all Research Division Transrex $500 \mathrm{~kW}$ magnet power supplies.

\section{ACKNOWLEDGEMENT}

These transductor upgrades would not have been possible without Age Visser's tutoring in magnetics over the years and his encouragement for me to write this paper. 


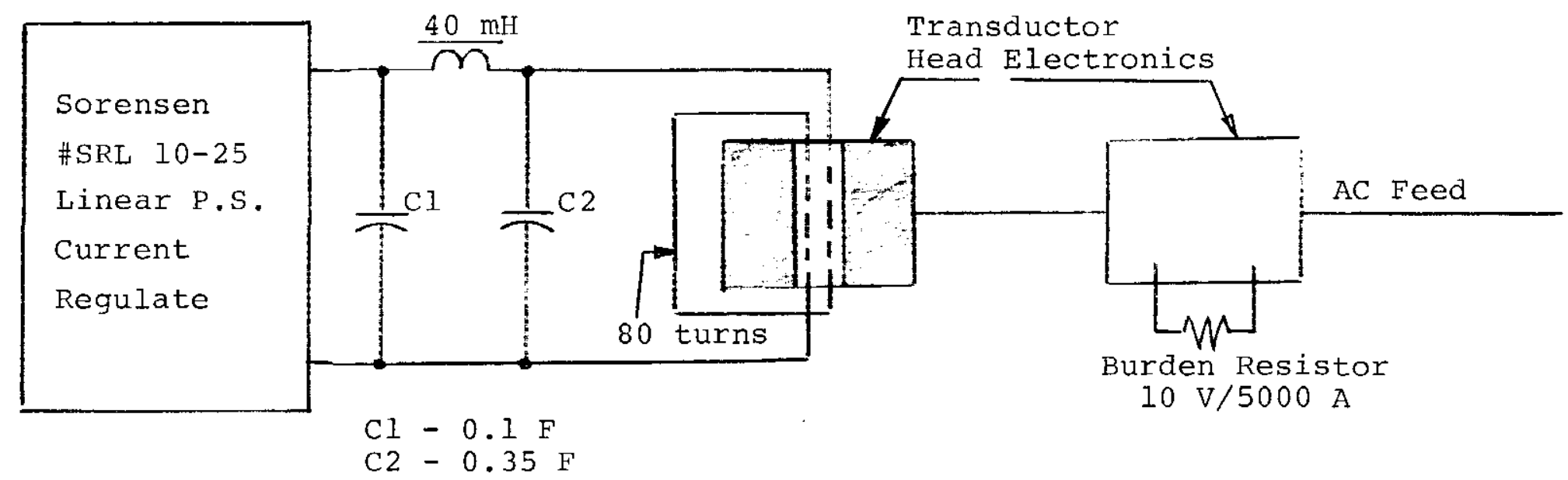

$\infty$

-- $\quad$ Spectrum analyzer was a H.P. 3561A Serial No. 2549A03152.

-- $\quad$ Transducer chassis was $500 \mathrm{~kW}$ Transrex Serial No. 73-099-9.

-- $\quad$ Transducer head was $500 \mathrm{~kW}$ Transrex Serial No. 71-104-14.

Scale factor for head and chassis is 10.0 Volts at 5000 Amp.

-- $\quad$ Scope measurements done with Tex. type 7633 with 7A22 diff. plug in and matched Tek P6055 probes.

-- $\quad$ All tests done with booster running but over a 2 month period. Booster creates $15 \mathrm{~Hz}$ disturbance in ac feed.

-- $\quad$ The measured voltage ripple across the 80 turn winding at 20.0 Adc was $60 \mathrm{~Hz}=2 \mathrm{ppm}, 15 \mathrm{~Hz}=0.12 \mathrm{ppm}, 9.2$ $\mathrm{Hz}=0.15 \mathrm{ppm}, 4.6 \mathrm{~Hz}=0.09 \mathrm{ppm}$.

FIGURE 1

TEST SET UP FOR NOISE MEASUREMENTS 


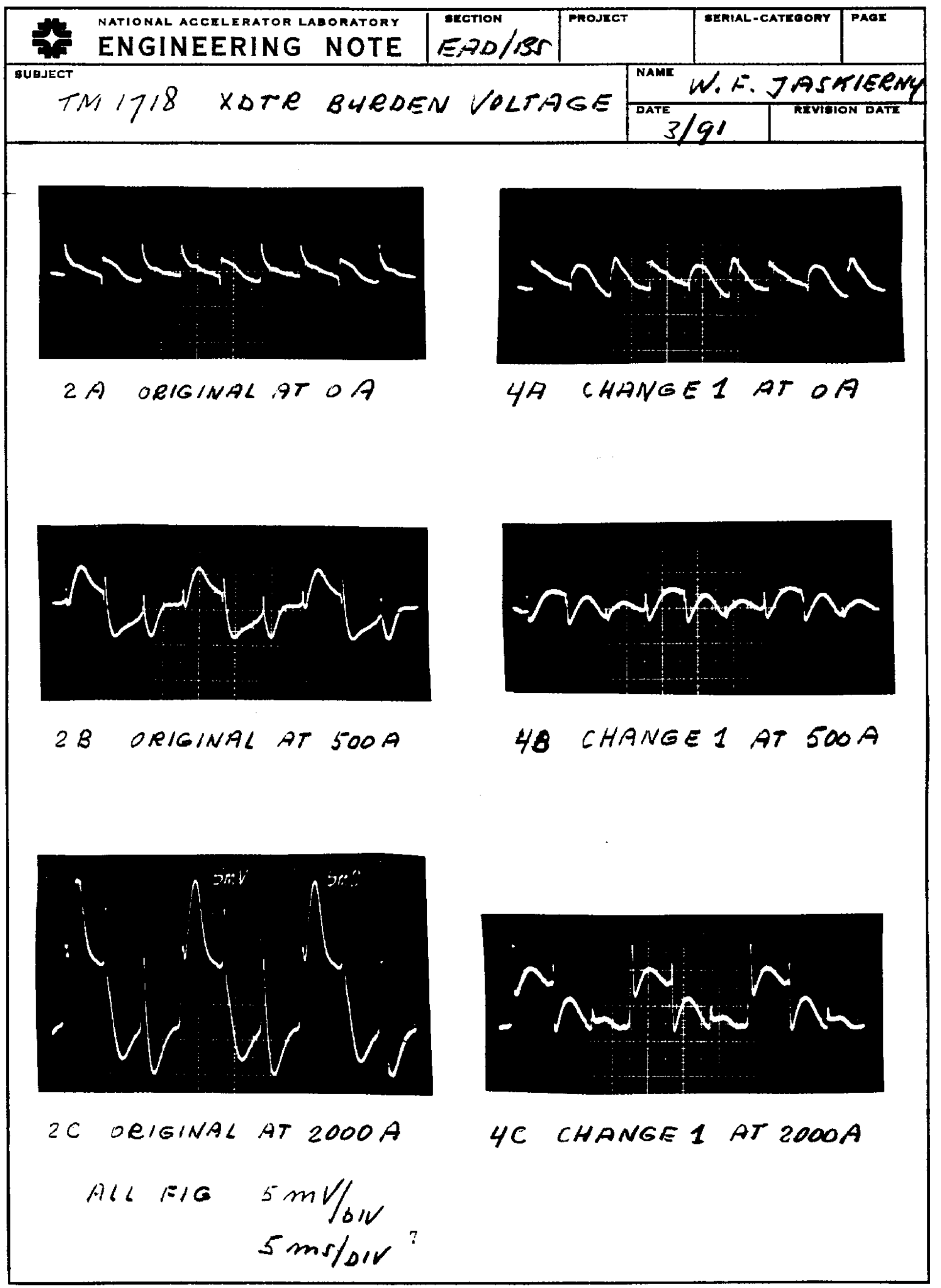




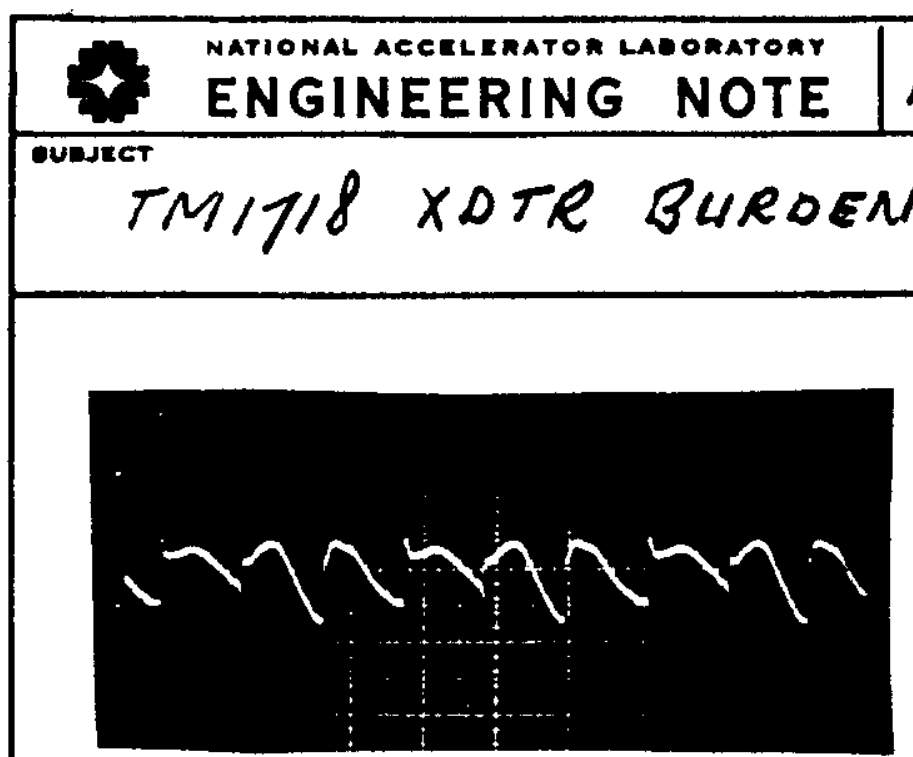

6A CHANGE I2 AT OA

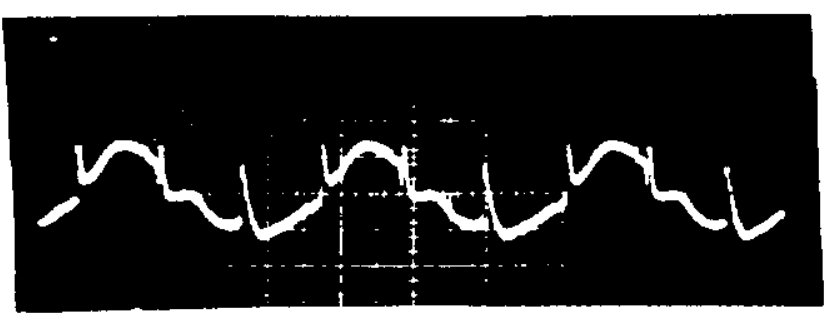

6B CHANGE IO AT 500/A

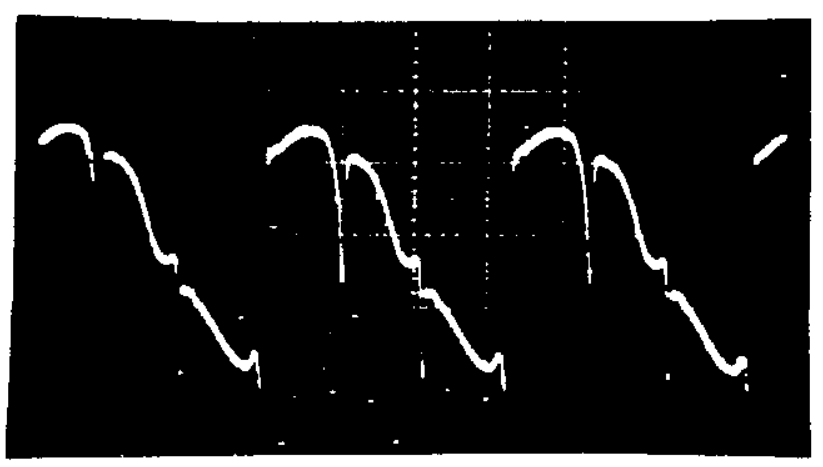

6C CHANGE 1,2 AT 2000A

$$
\begin{array}{r}
\text { ALL FIC } 5 \text { mVloIV } \\
5 \mathrm{~ms} / 0 \text { IV }
\end{array}
$$

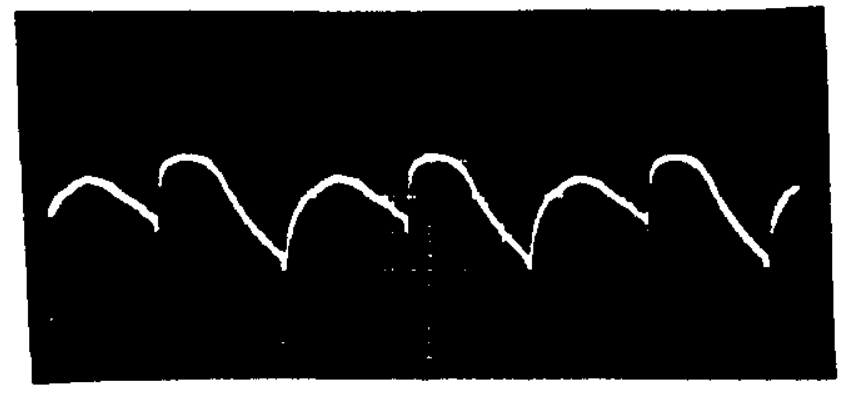

TA CHANGE 3333 AT OA

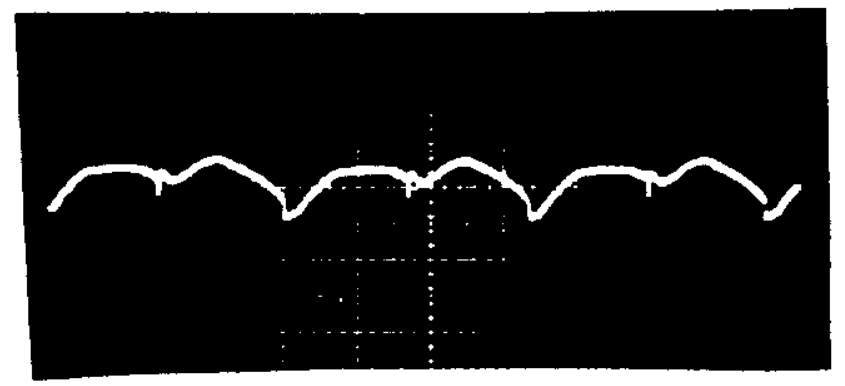

78 CHANGE $1,2,3$ AT 500A

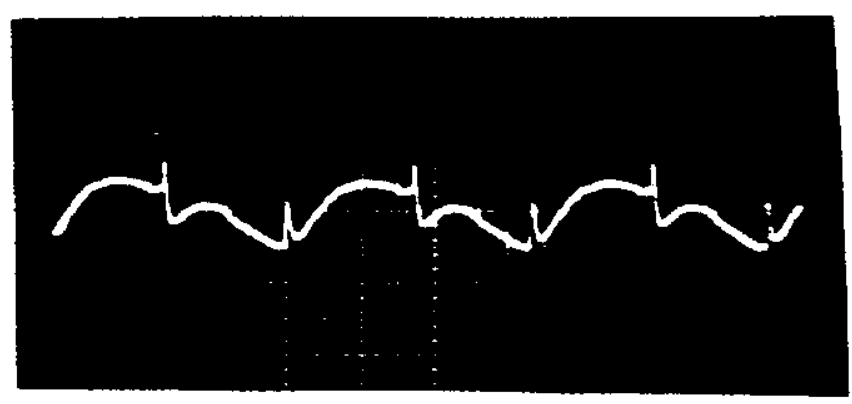

7C CHANGE 2,3 AT 2000A 


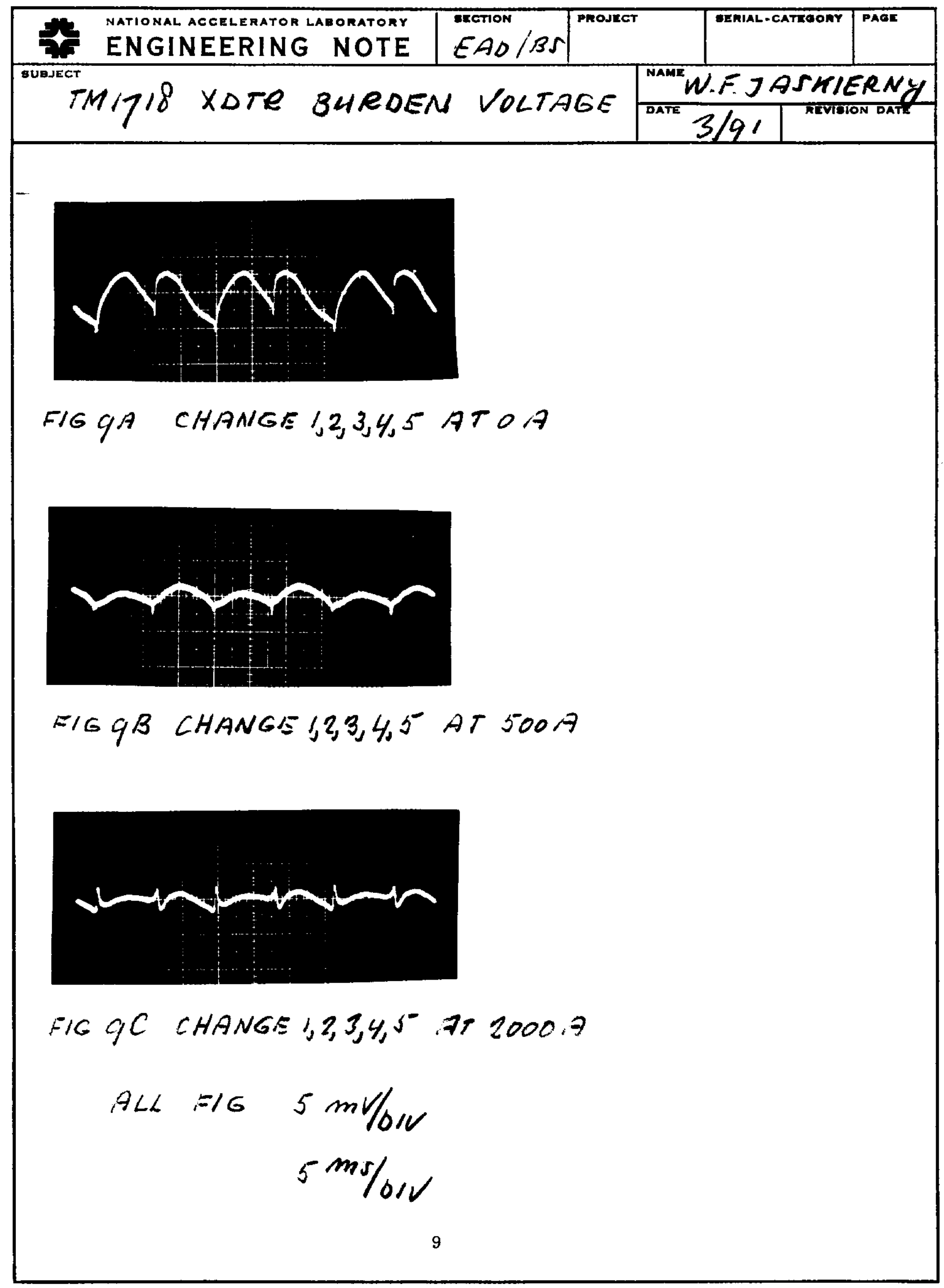




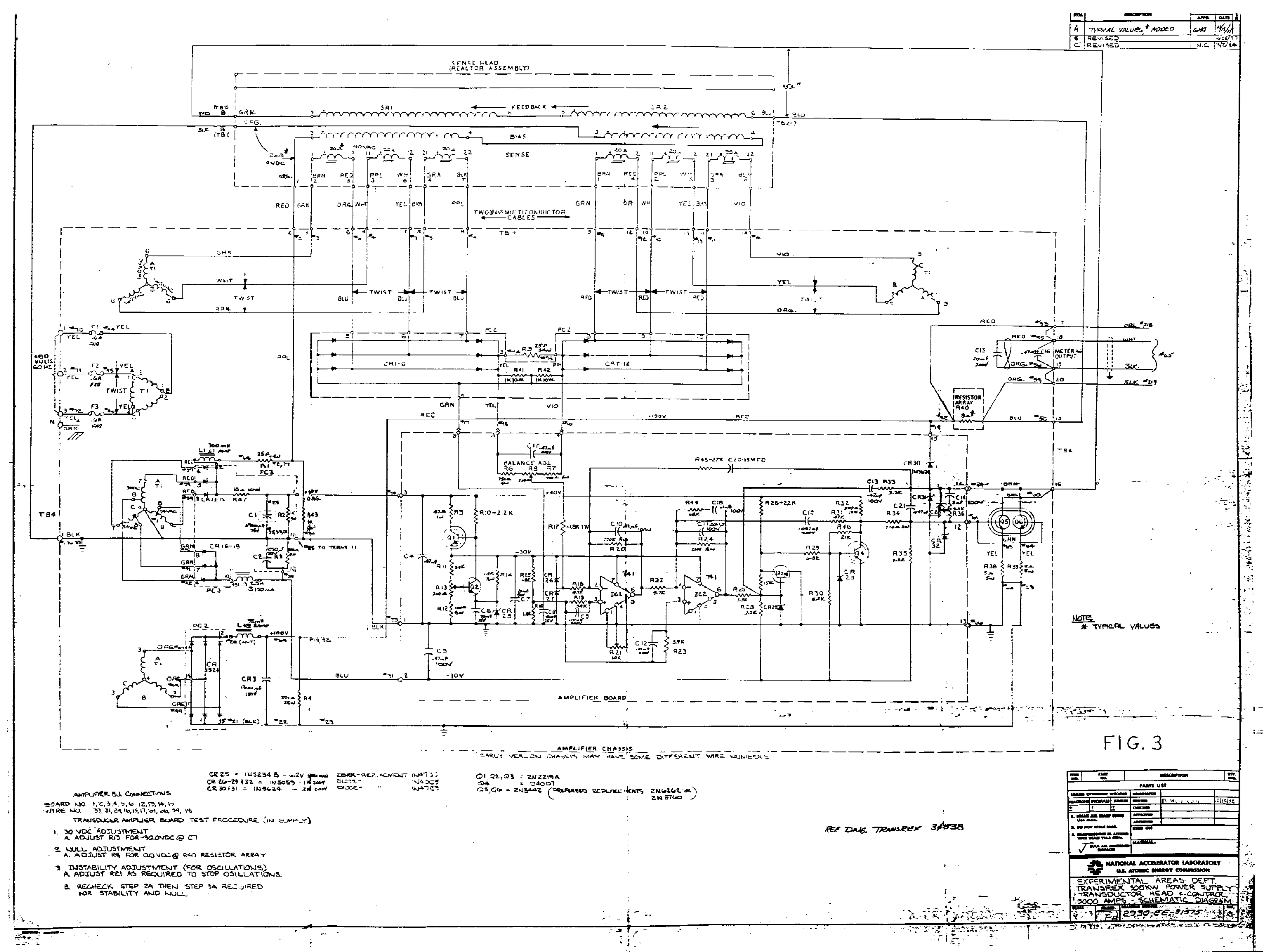




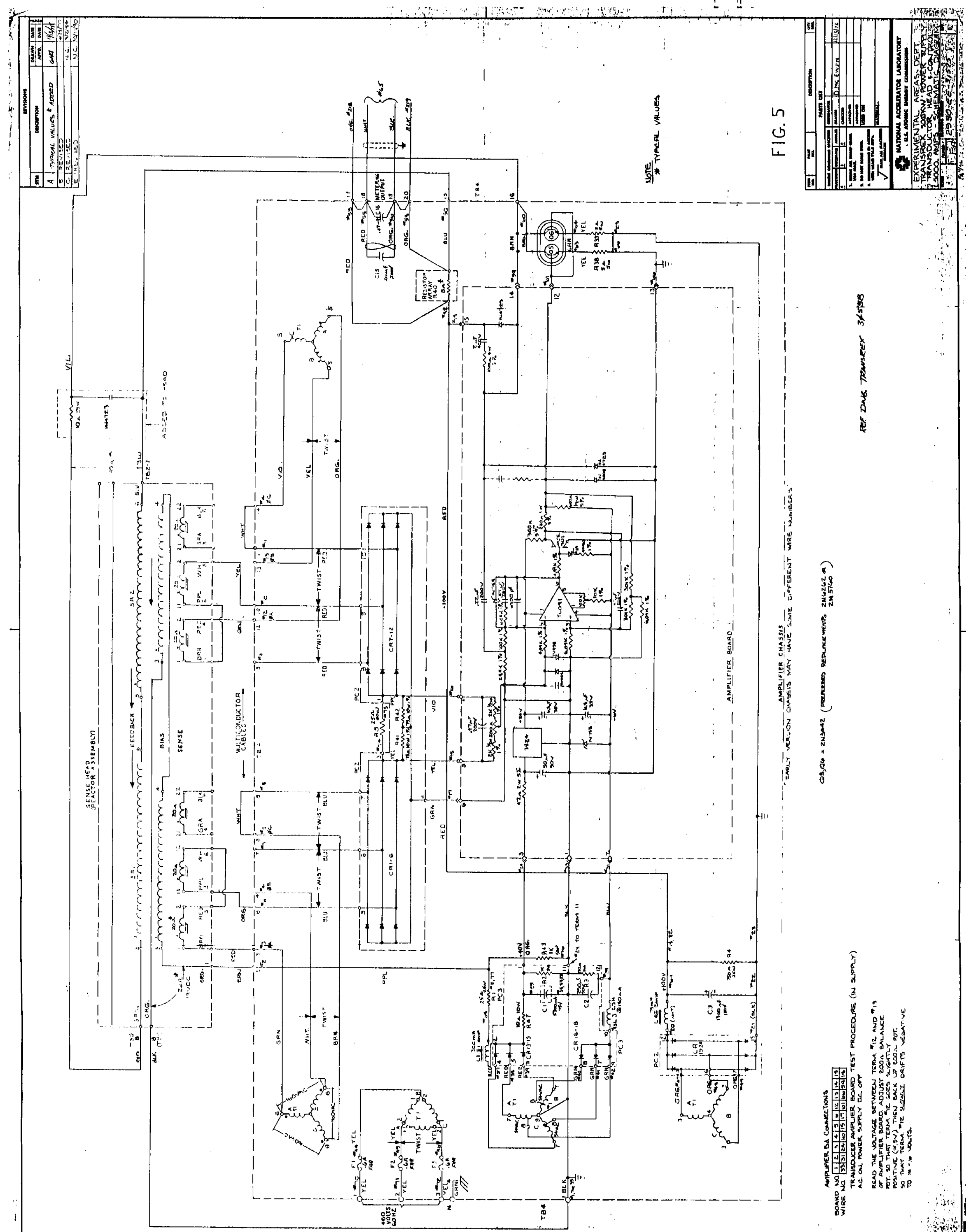




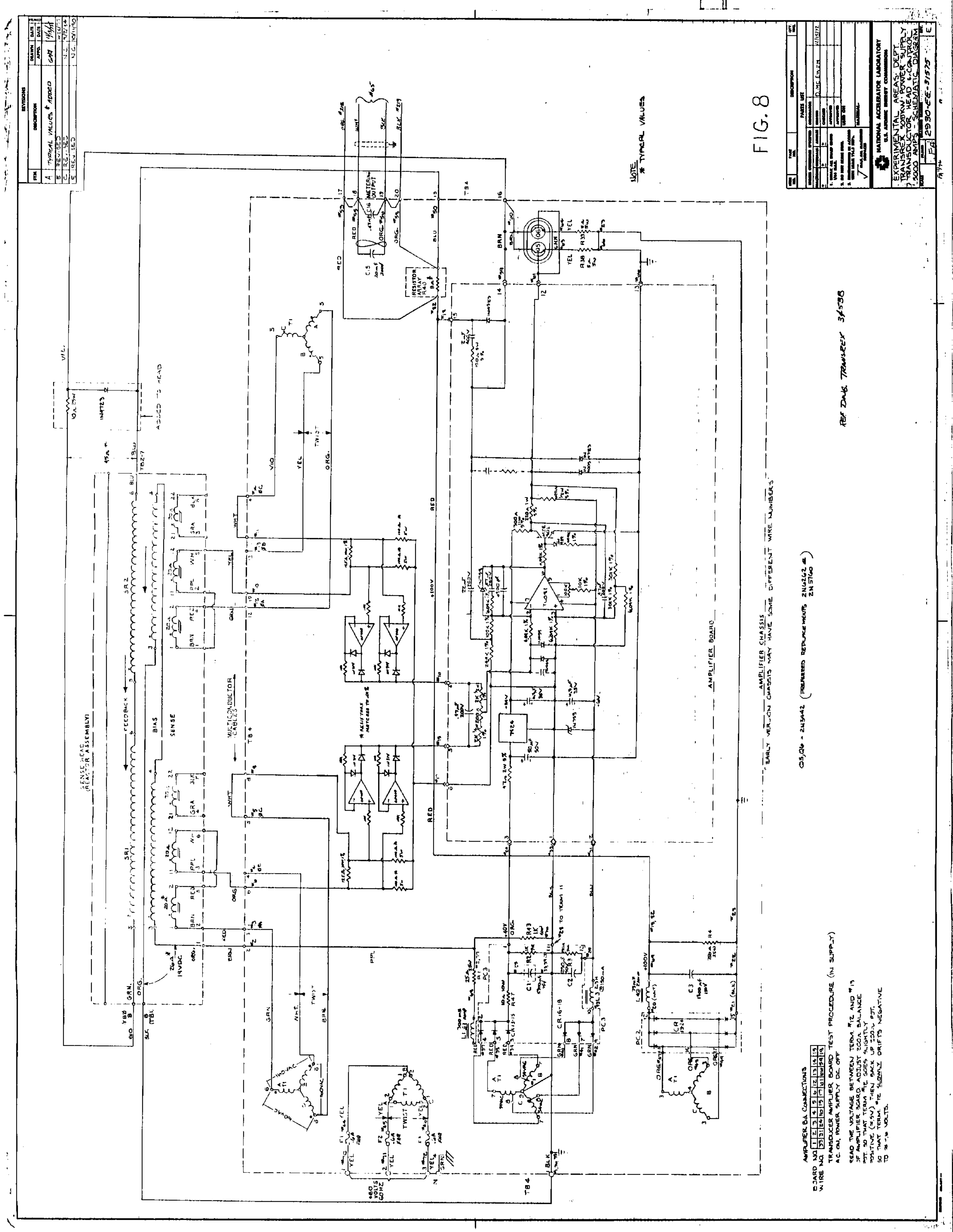

